\title{
Thermal Barrier Coatings with Interface Modified by 3D Mesh Patterns: Failure Analysis and Design Optimization
}

DOI:

10.1111/jace. 15386

\section{Document Version}

Accepted author manuscript

Link to publication record in Manchester Research Explorer

\section{Citation for published version (APA):}

Xiao, P., Luo, L., Shan, X., Guo, Y., Zhao, C., Wang, X., Zhao, X., \& Guo, F. (2018). Thermal Barrier Coatings with Interface Modified by 3D Mesh Patterns: Failure Analysis and Design Optimization. Journal of the American Ceramic Society. https://doi.org/10.1111/jace.15386

\section{Published in:}

Journal of the American Ceramic Society

\section{Citing this paper}

Please note that where the full-text provided on Manchester Research Explorer is the Author Accepted Manuscript or Proof version this may differ from the final Published version. If citing, it is advised that you check and use the publisher's definitive version.

\section{General rights}

Copyright and moral rights for the publications made accessible in the Research Explorer are retained by the authors and/or other copyright owners and it is a condition of accessing publications that users recognise and abide by the legal requirements associated with these rights.

\section{Takedown policy}

If you believe that this document breaches copyright please refer to the University of Manchester's Takedown Procedures [http://man.ac.uk/04Y6Bo] or contact uml.scholarlycommunications@manchester.ac.uk providing relevant details, so we can investigate your claim.

\section{OPEN ACCESS}


Thermal Barrier Coatings with Interface Modified by 3D Mesh Patterns: Failure Analysis and Design Optimization

Lirong Luo ${ }^{\mathrm{a}}$, Xiao Shan ${ }^{\mathrm{a}}$, Yi Guo ${ }^{\mathrm{c}}$, Chunshan Zhao ${ }^{\mathrm{a}}$, Fangwei Guo ${ }^{\mathrm{a}}$, Xin Wang ${ }^{\mathrm{b}}$, Xiaofeng Zhao ${ }^{\mathrm{a}^{*}}$ and Ping Xiao ${ }^{\mathrm{c}}$

${ }^{a}$ Shanghai Key Laboratory of Advanced High-temperature Materials and Precision Forming, Shanghai Jiao Tong University, Shanghai 200240, China

${ }^{b}$ Konca Solar Cells Co., Ltd, Wuxi 214000, China

${ }^{c}$ School of Materials, University of Manchester, Grosvenor Street, Manchester M1 $7 H S, U K$

\begin{abstract}
Surface patterning of the bond coat using a three-dimensional mesh offers a promising approach to improve the durability of the thermal barrier coatings (TBCs), in which the geometry parameters of the mesh play a vital role. The objective of this work is to investigate the failure behavior of the air-plasma sprayed TBCs with mesh, and to identify the optimal mesh design. The study revealed that the failure sequence of the TBCs with mesh patterns consisted of (I) initiation of the interfacial and ridge cracks (around the top of the mesh); (II) cracks propagation and buckling of the YSZ layer; (III) interfacial cracks deflection and coalescence with ridge cracks, leading to final
\end{abstract}

\footnotetext{
${ }^{*}$ Corresponding author: Xiaofeng Zhao

Tel./fax: +86-21-54742561.
} 
spallation. The critical parameters governing each step of the failure sequence were discussed and proposed. For a typical TBCs with YSZ thickness about $200 \mu \mathrm{m}$, the critical mesh height $h$ and spacing length $L$ is about $110 \mu \mathrm{m}$ and $7 \mathrm{~mm}$ respectively when the mesh width $w$ is fixed at about $480 \mu \mathrm{m}$.

Keywords: thermal barrier coatings (TBC), failure, interfaces, stress.

\section{Introduction}

Thermal barrier coatings (TBCs) are used to provide thermal gradient between high temperature gas and metallic engine components, enabling higher operating temperature and improving efficiency and performance. ${ }^{1,2}$ The conventional TBCs consist of a thermal insulating ceramic top coat and an aluminum containing metallic bond coat on superalloy substrates. During high temperature service, a thermally grown oxide (TGO) layer is developed at the top coat/bond coat interface due to the oxidation of the bond coat. A uniform and defect-free $\alpha-\mathrm{Al}_{2} \mathrm{O}_{3}$ TGO layer is preferred for retarding further bond coat oxidation and providing good adhesion with the top coat. ${ }^{3}$ Residual stress stemming from the thermal misfit between different layers and the TGO growth occurs and accumulates during thermal cycling. As a result, interface cracks nucleate and propagate which may lead to spallation either locally or even the entire top coat. Therefore, the durability of TBCs is still an overriding concern. The durability of a coating-substrate system depends strongly on the adhesion strength at the interface. The mechanical anchoring (or interlocking) is usually recognized as one of the main contributors to the bonding strength of the interface in TBCs., ${ }^{4,5}$ 
Therefore, many efforts have been devoted to modifying the interface structure in order to promote the interface adhesion and reduce the tendency of failure. For example, a grid of grooves or ribs were deliberately engineered in TBC system with yttria stabilized zirconia (YSZ) layer directly deposited on top of PWA 1484 substrate without bond coat. ${ }^{6}$ It was found that the substructures extend the lifetime of the coating considerably. Kramer et al, deliberately fabricated texture with holes at the interface of Ni-Al bond coats and substrates. ${ }^{5}$ In this way, the interface adherence is tripled. In previous work, mesh patterns at the $8 \mathrm{YSZ} / \mathrm{NiCoCrAlY}$ bond coat interface were introduced by laser powder deposition (LPD) method. ${ }^{7}$ It proved that mesh patterning is effective in impeding the propagation of interface cracks and could dramatically improve the thermal cycling lifetime of the air-plasma sprayed (APS) TBCs. Meanwhile, it was found that the parameters such as mesh height $h$ and spacing length $L$ are of great importance.

In this work, we aim to achieve a fundamental understanding on the failure behavior of the APS TBCs with mesh patterns. Meshes with different height $h$ and spacing length $L$, were applied between the bond coat and the substrate. Thermal cycling tests were carried out to evaluate the effects of the mesh parameters on the failure behavior and the lifetime of the APS TBCs. Based on the experimental observations, analytical models were employed to explain the failure phenomenon and to predict the optimal parameters of the mesh. 


\section{Experimental procedure}

\subsection{Materials and processing techniques}

Hastelloy ${ }^{\circledR} \mathrm{X}$ polycrystalline superalloy was used as substrate, which was cleaned with alcohol and grit blasted with grade 60 alumina. The mesh patterns were directly deposited on the surface of the substrate using LPD with continuous wave laser (YLS-2000, IPG Photonic, USA). The diameter of the laser spot is about $480 \mu \mathrm{m}$ which is focused using a lens with $200 \mathrm{~mm}$ focal length. The feedstock powder (NiCoCrAlY, Amdry 365-2, Sulzer Metco Inc., USA) was delivered by coaxial feeding nozzles with $10 \mathrm{~mm} / \mathrm{s}$ scan velocity and $3 \sim 4 \mathrm{~g} / \mathrm{min}$ feed rate. During meshing, the lens was blown by argon gas with a flow rate of $6 \mathrm{~L} / \mathrm{min}$ to avoid contamination. Subsequent to the LPD process, a NiCoCrAlY bond coat (Amdry 365-2, Sulzer Metco Inc., USA) and an $8 \mathrm{wt} \%$ yttria-stabilized zirconia top coat (Metco 204B-NS, Sulzer Metco Inc., USA) were deposited using APS accordingly. A schematic of the meshed surface and the cross-sectional view are shown in Fig. 1. Conventional TBCs without the mesh patterns were prepared under the same conditions for comparison.

(a)

(b)

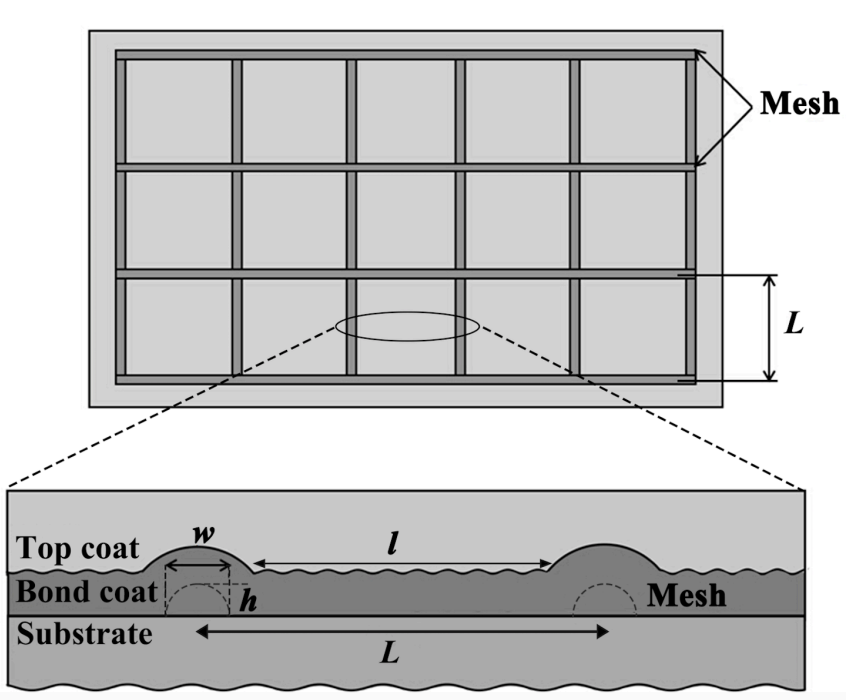


Fig. 1. The schematics of the (a) surface and (b) cross-section of the TBCs with mesh patterns.

\subsection{Thermal cycling tests}

The specimens were cut into plates with a dimension of $20 \mathrm{~mm} \times 20 \mathrm{~mm} \times 5 \mathrm{~mm}$. Ten of each $\mathrm{TBC}$ system were subjected to cyclic heat treatment in a furnace under atmospheric environment. Each thermal cycling test consists of 10 min heating-up from room temperature to $1150{ }^{\circ} \mathrm{C}, 24 \mathrm{~h}$ holding at $1150{ }^{\circ} \mathrm{C}$ and fan-assisted air cooling to ambient temperature after being removed from the furnace.

\subsection{Characterization}

The spalled area of the YSZ layer after thermal cycling were characterized using an optical microscope (BX-51M, Olympus, Japan). The morphology of the cross-sections and the microstructures of the coatings were characterized using scanning electron microscopy (SEM, FEI Quanta 200, Netherlands). Prior to the measurements, the samples were mounted in a transparent epoxy resin and polished with grit paper and diamond paste down to $0.05 \mu \mathrm{m}$. Quantitative phase analysis of the YSZ layer after oxidation was performed using X-ray diffractometer (XRD, Ultima IV, Rigaku, Japan) at $30 \mathrm{kV}$ with $\mathrm{Cu} K_{\alpha}$ radiation. The spectra were collected in the $2 \theta$ range of $27 \sim 33^{\circ}$ at a step size of $0.02^{\circ}$ with a scanning speed of $0.5^{\circ} / \mathrm{min}$. Raman spectroscopy were employed to characterize the stress distribution using a confocal Raman microprobe (LabRAM HR, Horiba Jobin Yvon, France) with 532 nm Nd:YAG laser. The position of each peak was evaluated through a deconvolution 
process using commercial Labspec peak fitting software (Labspec, Horiba Jobin Yvon, France). The residual stress was calculated based on the peak shift from a stress-free reference on a detached YSZ layer.

\section{Results}

\subsection{The microstructure of the as-deposited APS TBCs with mesh patterns}

The SEM micrographs of the cross-sections of the as-deposited TBCs with and without the mesh patterns are shown in Fig. 2. In this experimental set, mesh height $h$ of $70 \mu \mathrm{m}, 140 \mu \mathrm{m}, 210 \mu \mathrm{m}$, and spacing length $L$ of $3 \mathrm{~mm}, 5 \mathrm{~mm}, 7 \mathrm{~mm}$ were used, which were selected based on a previous work. ${ }^{7}$ Mesh width $w$ of all specimens is about $480 \mu \mathrm{m}$, which is limited by the diameter of the nozzle of the LPD system. The thicknesses of top coats and bond coats are $200 \pm 40 \mu \mathrm{m}$ and $150 \pm 35 \mu \mathrm{m}$ respectively, as averaged by at least 30 measurements with a spacing of $30 \mu \mathrm{m}$.
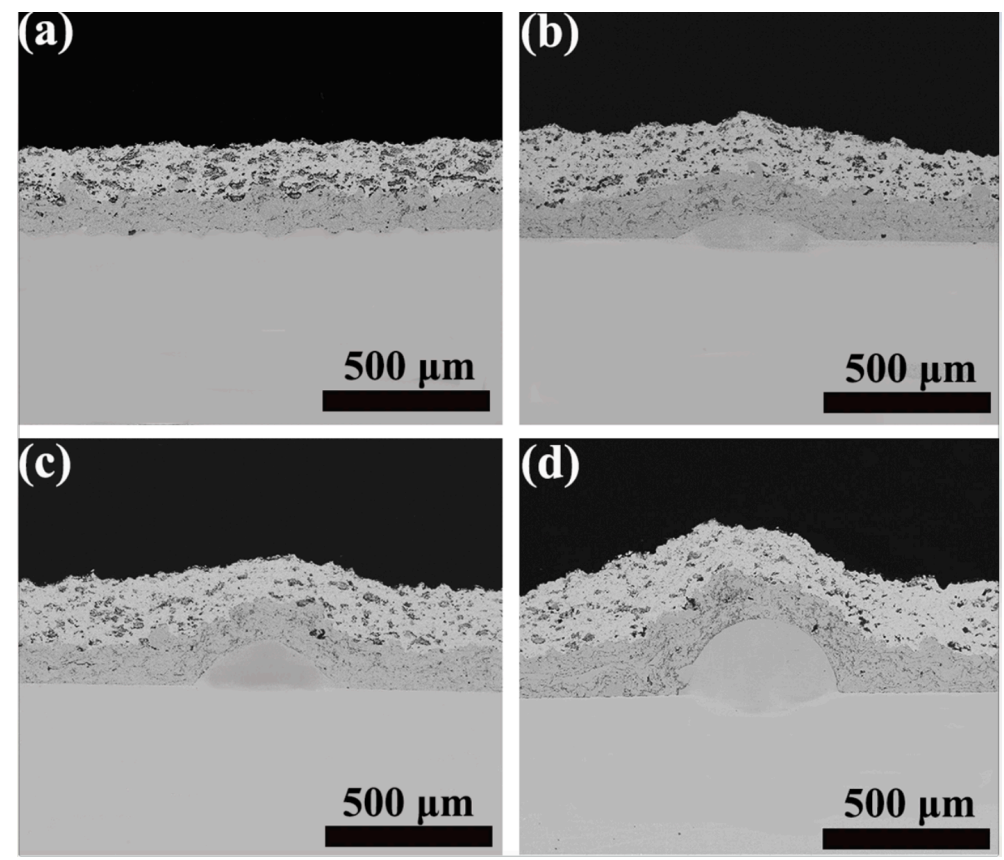
Fig. 2. The cross-sections of the as-deposited (a) conventional TBCs and TBCs with mesh height of (b) $70 \mu \mathrm{m}$, (c) $140 \mu \mathrm{m}$ and (d) $210 \mu \mathrm{m}$.

\subsection{Degree of Spallation}

The thermal cycling tests were carried out at $1150{ }^{\circ} \mathrm{C}$ to evaluate the effect of mesh parameters on the durability of TBCs. After 3024 -h cycles at $1150{ }^{\circ} \mathrm{C}$, the spallation degree (defined as the ratio of the detached area to the total area of the YSZ coating) of the APS TBCs as a function of the mesh height $h$ and spacing length $L$ is presented in Fig. 3, and the data for conventional APS TBCs (without mesh) after the same thermal treatments are also presented for reference. The spallation degree is measured based on the contrast between the detached (including the areas at the ridge of the mesh, the areas between the meshes, and the edges of the samples) and the intact areas using Image J. Each data shown in Fig. 3 is averaged over 10 samples and the error bar shows the standard deviation. It should be noted that the spallation degree of the conventional TBCs was approximately 74\%, which was significantly higher than those with mesh patterns, indicating that the mesh plays an important role in enhancing the durability of the TBCs. The samples with mesh height of $140 \mu \mathrm{m}$ and $210 \mu \mathrm{m}$ showed much less spallation than those of $70 \mu \mathrm{m}$. For different mesh spacing, the degree of spallation does not show significant difference. 


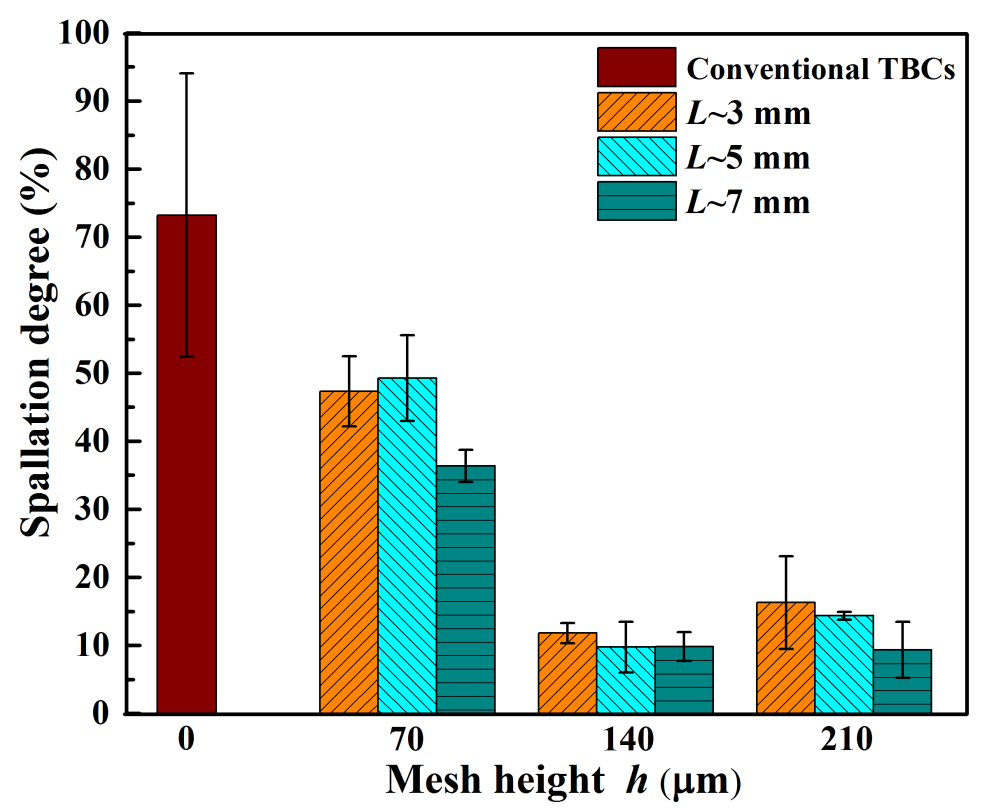

Fig. 3. The spallation degree of the APS TBCs as a function of mesh height $h$ and spacing length $L$ after $3024-\mathrm{h}$ cycles at $1150^{\circ} \mathrm{C}$.

\subsection{Microstructure after thermal cycling}

The surface topographies of the samples after 3024 -h cycles at $1150{ }^{\circ} \mathrm{C}$ are presented in Fig. 4. For simplicity and clarity, the mesh height (in the unit of $\mu \mathrm{m}$ ) and spacing length (in the unit of $\mathrm{mm}$ ) of each sample are labeled at the top-right corner. The results show that: (1) the samples with mesh height of $70 \mu \mathrm{m}$ spalled at large scale through edge delamination, which is similar to the conventional TBCs; (2) the samples with mesh height of $210 \mu \mathrm{m}$ detached predominantly around the ridge of the mesh; (3) the YSZ layer of TBCs with mesh height of $140 \mu \mathrm{m}$ demonstrated the longest durability and stayed almost intact except for the area near the edge, which is consistent with Fig. 3 that the degrees of spallation of the $140 \mu \mathrm{m}$ patterned TBCs are slightly lower than that of the $210 \mu \mathrm{m}$ ones. Based on the results in Fig. 4, the degree of spallation decreased with the increase of the spacing length $L$ for the samples with 
mesh height of $210 \mu \mathrm{m}$. This is attributed to the fact that the TBCs with mesh height of $210 \mu \mathrm{m}$ predominantly detached around the ridge of the mesh and the quantity of mesh per unit area decreases with the increase of the mesh spacing.
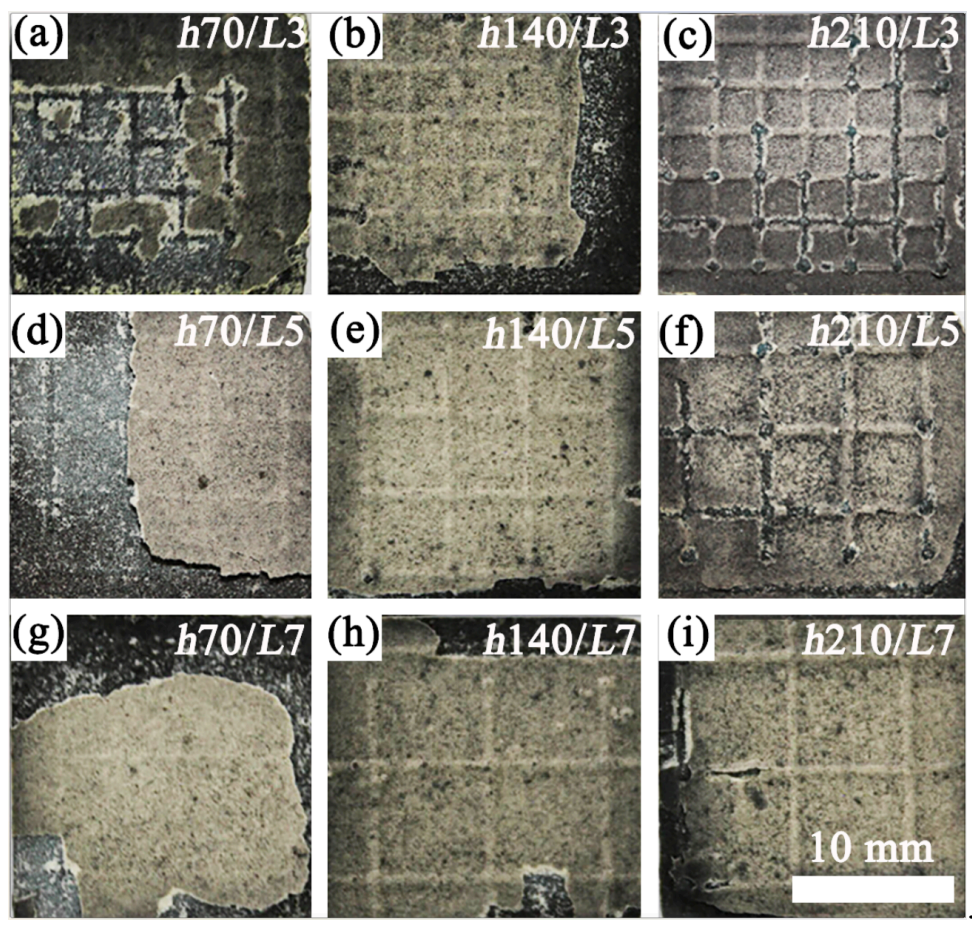

Fig. 4. The surface topographies of the APS TBCs with mesh after 30 24-h cycles at $1150{ }^{\circ} \mathrm{C}$

The cross-sections of the TBCs with different mesh height after 30 24-h cycles at $1150^{\circ} \mathrm{C}$ are presented in Fig. 5. The average TGO layer thicknesses of the samples is approximately $12.1 \pm 1.5 \mu \mathrm{m}$. Fig. 5a shows that large-scale edge initiated delamination occurred at the YSZ/TGO interface in the conventional TBCs. The interfacial crack conformed to the shape of the mesh but still propagated along the TGO interface when the height of the mesh was $70 \mu \mathrm{m}$ (Fig. 5b), which indicates that the mesh height of $70 \mu \mathrm{m}$ is not high enough to impede the crack propagation. For the samples with mesh height of $140 \mu \mathrm{m}$, no edge initiated delamination was observed. 
However, horizontal and vertical cracks formed around the ridge of the mesh (Fig. 5c). Detachment of the YSZ layer occurred around the ridge of the mesh when the mesh height increased to $210 \mu \mathrm{m}$. This is related to the stress redistribution around the curved surface of mesh. ${ }^{8}$
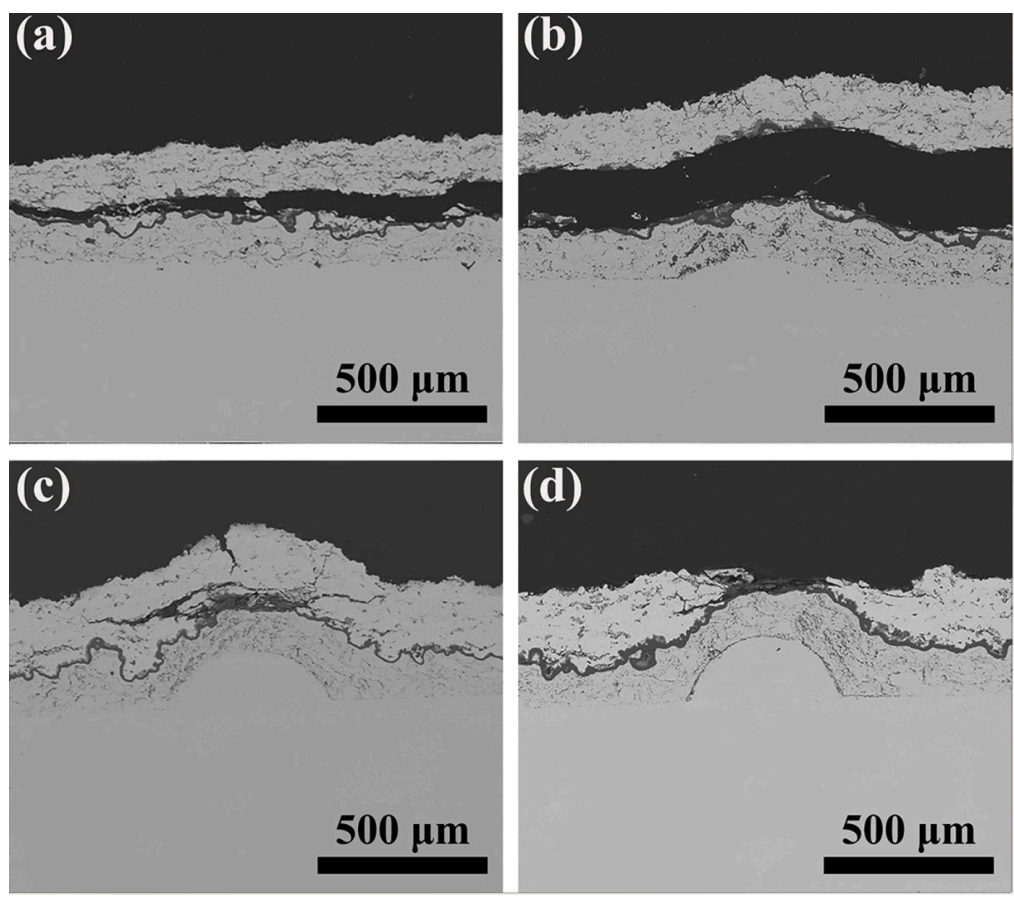

Fig. 5. The cross-section micrographs of (a) the conventional TBCs and the TBCs with mesh height of (b) $70 \mu \mathrm{m}$, (c) $140 \mu \mathrm{m}$ and (d) $210 \mu \mathrm{m}$ respectively, after 30 24-h cycles at $1150{ }^{\circ} \mathrm{C}$.

When the mesh height was over $70 \mu \mathrm{m}$, no spallation was observed between the meshes. However, buckling of the YSZ layer between the meshes occurred when the spacing length is over $3 \mathrm{~mm}$ ( $5 \mathrm{~mm}$ and $7 \mathrm{~mm}$ in the present work). The surface and the cross-section of the buckled sample (with spacing of $7 \mathrm{~mm}$ and height of $210 \mu \mathrm{m}$ ) are shown in Fig. 6a. To quantify the geometry of the buckle, the height of the topcoat 
surface as a function of the distance around the buckled area was measured using optical microscope (with magnification of $50 \times$ ). ${ }^{9}$ The three-dimensional graph in Fig. $6 \mathrm{~b}$ showed axisymmetric circular delamination. The bottom of the buckled YSZ layer showed only traces of the TGO, suggesting that the failure occurred predominantly at the YSZ/TGO interface (Fig. 6c). Raman spectroscopy measurement on the surface of the buckle along the line marked in Fig. 6b illustrates that the residual stress has changed from compressive to tensile from the edge to the top of the buckled region. The tensile stress associated with the bending is likely to initiate and extend cracks through the YSZ layer, leading to spallation. ${ }^{10}$ Therefore, analyzing the buckling behavior is of great importance.
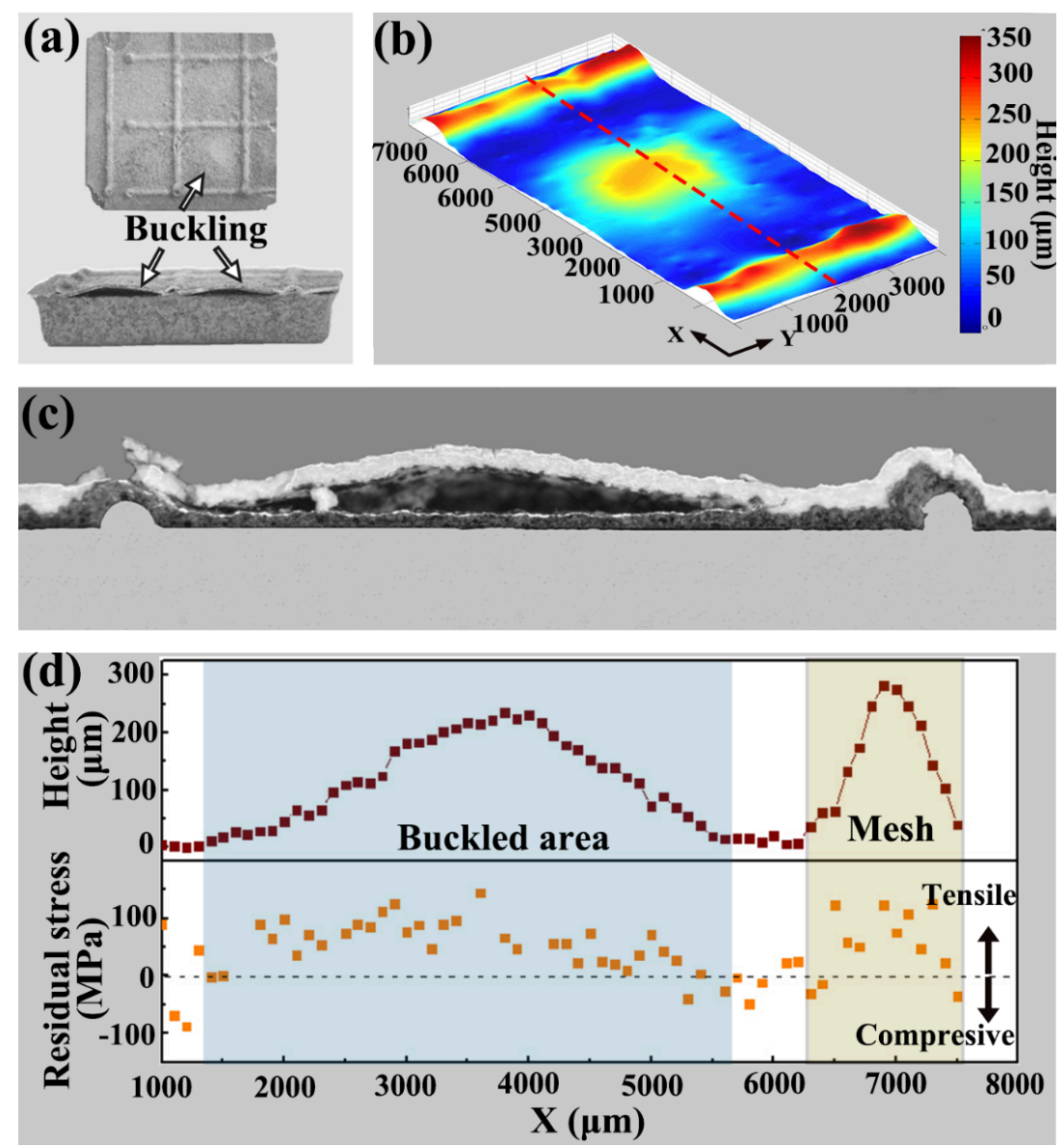

Fig. 6. The (a) surface and cross-section of the buckled sample with mesh spacing of 
$7 \mathrm{~mm}$ and height of $210 \mu \mathrm{m}$; (b) the three-dimensional plot of the height of the buckled area; (c) the SEM image of polished cross-section; (d) the height profile and stress along the dash line marked.

\section{Discussion}

The enhanced durability of the TBCs with mesh patterns over the conventional TBCs (Fig. 3) could be attributed to the blocking effect of the mesh on the propagation of interfacial cracks. The failure behavior of the TBCs with mesh varies depending on the parameters such as mesh height and spacing length. A schematic illustrating the failure sequence is shown in Fig. 7 as described as follows: (I) The coating is subjected to a compressive residual stress at ambient temperature after thermal cycling. This stress results in the nucleation and propagation of cracks at the TGO/TBC interface. Meanwhile, the stress redistributes around the ridge of the mesh due to the curved surface and initiates cracks (designated as ridge cracks). ${ }^{8}$ (II) The YSZ layer buckles when the diameter of the interfacial cracks exceeds a critical value $b_{\mathrm{c}}$. (III) the tips of the interfacial crack are blocked and deflected by the ridge of the mesh and then coalesce with the ridge cracks, causing large scale delamination. The critical factors governing each step will be discussed as follows. 


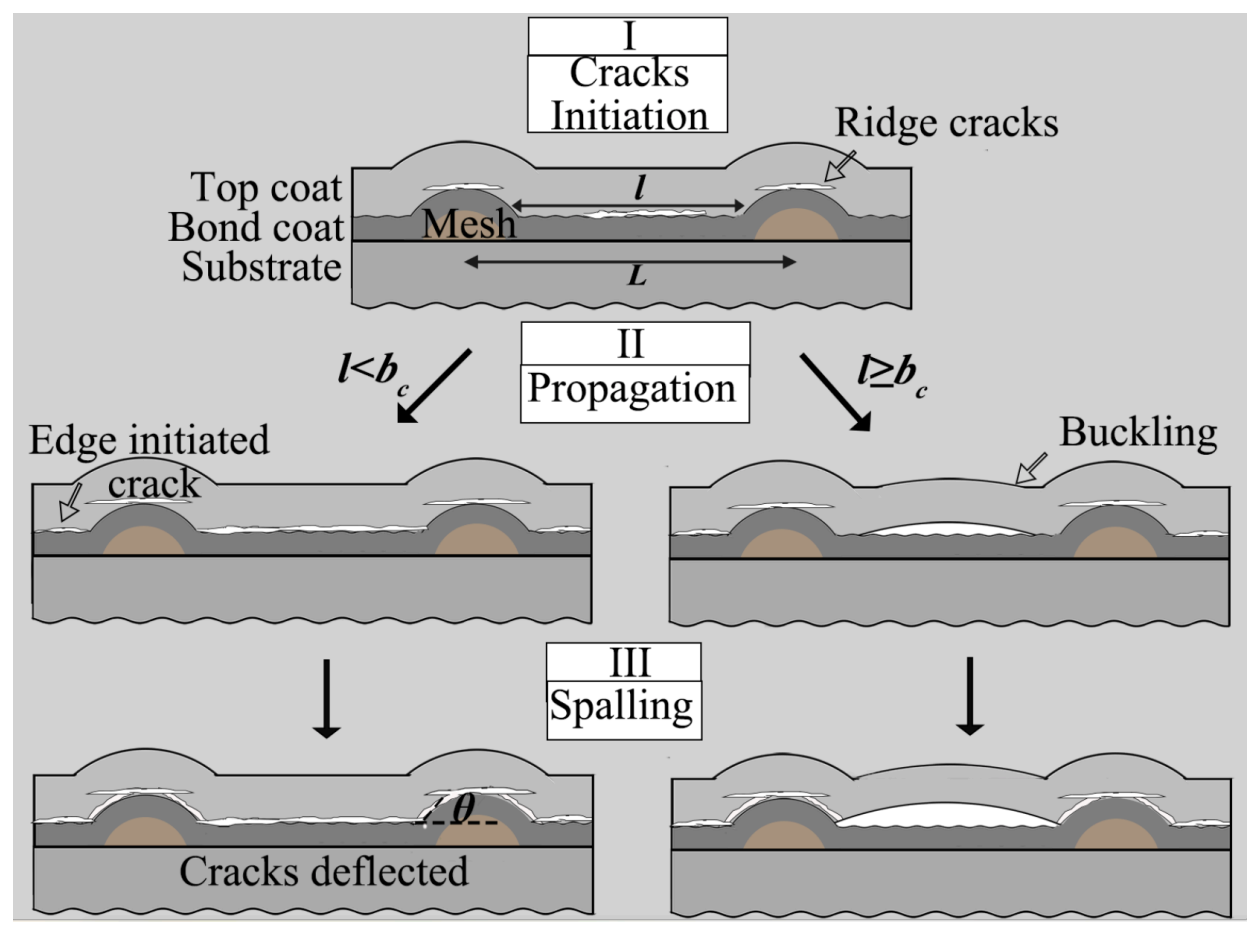

Fig. 7. A schematic illustrating the falling sequence of the TBCs with mesh patterns detaching from the substrate under compressive stress.

\subsection{Initiation of the interfacial and the ridge cracks}

During cooling, cracks tend to initiate at the interface of top coat/bond coat between the meshes and at the ridge of the mesh. The initiation of the interfacial cracks between the meshes is not addressed in present study, since it is analogous to the phenomenon in conventional TBCs and has already been discussed extensively. ${ }^{11,12}$

As shown in Fig. 4, local detachment of the YSZ layer occurred around the ridge of the mesh after thermal treatment with the mesh height of $210 \mu \mathrm{m}$, while no apparent detachment occurs at this region when the mesh height is lower than $210 \mu \mathrm{m}$. This is attributed to the radial tensile stress caused by the stress redistribution on the curved surface of the meshes. This tensile stress will accelerate the formation of the cracks around the ridge of the mesh. Meanwhile the magnitude of this tensile stress is related 
to the curvature.

For the system studied, the curvature of the mesh is controlled by the ratio between the mesh height and width, $h / w$. The mesh width of each sample is about $480 \mu \mathrm{m}$. Therefore, only the effect of the mesh height on the magnitude of the tensile stress will be discussed. A three-concentric-circle model was adopted to analyze the tensile stress $\sigma_{r}$ at the interface between the TGO and the YSZ layer around the mesh ridge, as illustrated in Fig. $8 .{ }^{13}$ The $\sigma_{r}$ can be written as:

$$
\sigma_{\mathrm{r}}=\frac{E_{\mathrm{tgo}}\left[P_{3}\left(\alpha_{\mathrm{tgo}}-\alpha_{\mathrm{bc}}\right)+P_{2}\left(\alpha_{\mathrm{tbc}}-\alpha_{\mathrm{tgo}}\right)\right] \Delta T}{P_{1} P_{2}-P_{3} P_{4}}
$$

where the parameters $P_{1}, P_{2}, P_{3}$ and $P_{4}$ are given by:

$$
\begin{gathered}
P_{1}=\frac{R_{2}^{2}+R_{1}^{2}}{R_{2}^{2}-R_{1}^{2}}-v_{\mathrm{tgo}}+\frac{E_{\mathrm{tgo}}}{E_{\mathrm{tbc}}}\left(\frac{R_{3}^{2}+R_{2}^{2}}{R_{3}^{2}-R_{2}^{2}}+v_{\mathrm{tbc}}\right) \\
P_{2}=\frac{R_{2}^{2}+R_{1}^{2}}{R_{2}^{2}-R_{1}^{2}}+v_{\mathrm{tgo}}+\frac{E_{\mathrm{tgo}}}{E_{\mathrm{sub}}}\left(1-v_{\mathrm{sub}}\right) \\
P_{3}=\frac{2 R_{1}^{2}}{R_{2}^{2}-R_{1}^{2}} \\
P_{4}=\frac{2 R_{2}^{2}}{R_{2}^{2}-R_{1}^{2}}
\end{gathered}
$$

where the $R_{1}, R_{2}$ and $R_{3}$ is the outer radius of the bond coat, TGO layer and YSZ layer, respectively. Subscripts "tbc" and "tgo" denote YSZ and TGO layer respectively. $E$ is the Young's modulus. $\alpha$ is the coefficient of thermal expansion. $\Delta T$ is the temperature change and in the current calculation, $\Delta T=1125^{\circ} \mathrm{C}$.

The radial tensile stress $\sigma_{r}$ as a function of the mesh height is shown in Fig. 8. It can be seen that the tensile stress increases with the mesh height and approaches a limit 
above $200 \mu \mathrm{m}$. Lower height of the mesh induces less tensile stress concentration and is therefore less likely to initiate cracks around the ridges.

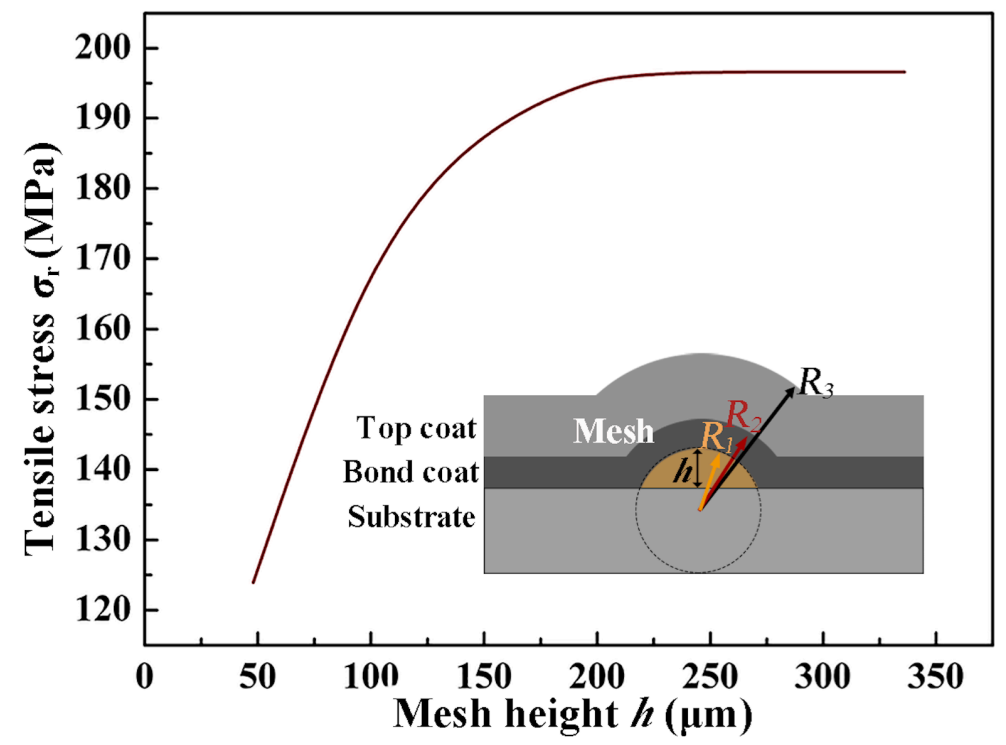

Fig. 8. The radial tensile stress $\sigma_{r}$ as a function of the mesh height $h$.

\subsection{Buckling}

The YSZ layer buckles when the diameter of the interfacial crack exceeds a critical value $b_{\mathrm{c}}$. For the YSZ layer between the meshes, stress was generated from three principle sources after thermal cycling: (I) thermal mismatch between the YSZ and the substrate during cooling, $\sigma_{\text {misfit }}$; (II) the growth of the TGO layer on the surface of the meshes, which induced a constraint stress on the YSZ top coat, $\sigma_{\text {constrain }}$; (III) tetragonal to monoclinic phase transformation of the YSZ after thermal cycling, $\sigma_{\mathrm{t}-\mathrm{m}}$. The thermal mismatch stress $\sigma_{\text {misfit }}$ between the substrate and YSZ layer can be estimated by: $:^{14}$

$$
\sigma_{\text {misfit }}=\frac{E_{\mathrm{tbc}}\left(\alpha_{\mathrm{sub}}-\alpha_{\mathrm{tbc}}\right) \Delta T}{\left(1-v_{\mathrm{tbc}}\right)}
$$

where the subscript "sub" denotes the substrate. The parameters of different layers adopted for the calculation are listed in Table $1 .^{15}$ 
Table. 1 Thermo-physical properties of different layers of the TBCs.

\begin{tabular}{cccc}
\hline & Yong's modulus $E(\mathrm{GPa})$ & Possion's ratio & \\
& 50 & $\nu$, & $\mathrm{CTE} \alpha\left(* 10^{-6} /{ }^{\circ} \mathrm{C}\right)$ \\
Top coat & 360 & 0.25 & 8 \\
TGO & 200 & 0.25 & 11 \\
Mesh/Bond coat & 200 & 0.3 & 16 \\
Substrate & 200 & 0.3 & 16 \\
\hline
\end{tabular}

The constrain stress $\sigma_{\text {constrain }}$ is related to the formation of the TGO layer on the surface of the meshes after oxidation. The TGO thickening on the mesh surface could introduce additional compression on the YSZ layer. The value of the Pilling-Bedworth ratio $\Phi$ for the formation of alumina in NiCoCrAlY is 1.28 . Thus, the net thickness increment due to the TGO formation is: $\Delta t=0.08 t_{\text {tgo }} \cdot{ }^{16}$ Therefore, the strain $\varepsilon_{\text {constrain }}$ caused by the increased thickness $\Delta t$ is:

$$
\varepsilon_{\text {constrain }}=\frac{2 \Delta t}{l}
$$

where $l=L-w$ is the average length between the adjacent meshes. This is analogous to applying a biaxial compressive stress to the YSZ layer between the meshes. The corresponding compressive stress $\sigma_{\text {constrain }}$ induced by TGO growth on the meshes is given by:

$$
\sigma_{\text {constrain }}=\varepsilon_{\text {constrain }} E_{\mathrm{tbc}}
$$

The calculated $\sigma_{\text {constrain }}$ as a function of the spacing length and the TGO thickness is shown in Fig. 9. It suggests that the $\sigma_{\text {constrain }}$ increases dramatically with the decrease of the spacing length and the TGO thickness when the spacing length is less than 5 
$\mathrm{mm}$, while it could be neglected when the spacing length exceeds $5 \mathrm{~mm}$.

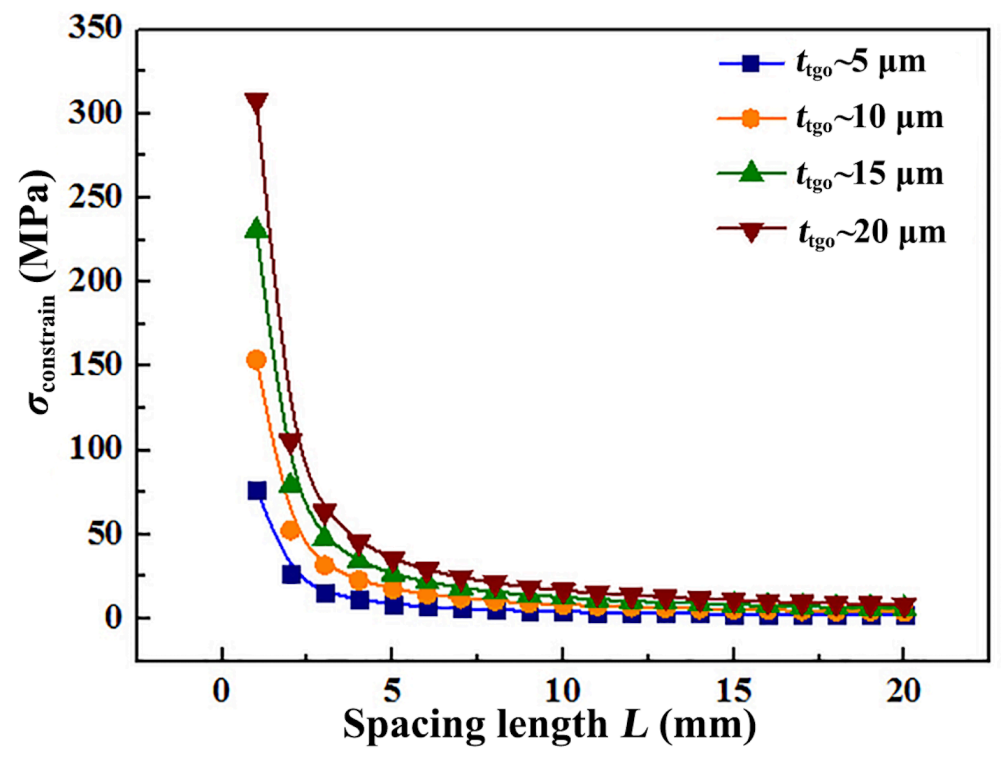

Fig. 9. The residual stress induced by TGO growth on mesh.

The stress related to phase transformation $\sigma_{\mathrm{t}-\mathrm{m}}$ is controlled by the volume fraction of monoclinic phase formed in the YSZ layer which is transformed from tetragonal YSZ after prolonged exposure at elevated temperature. ${ }^{17}$ The $t-m$ transformation is known to be accompanied by a volume expansion of about $5 \%{ }^{18}$ The XRD measurement was carried out to identify the volume fraction of the monoclinic YSZ by: ${ }^{19}$

$$
f_{\mathrm{m}}=\frac{1.311 X_{\mathrm{m}}}{1+0.311 X_{\mathrm{m}}}
$$

with

$$
X_{\mathrm{m}}=\frac{I_{\mathrm{m}}(11 \overline{1})+I_{\mathrm{m}}(111)}{I_{\mathrm{m}}(11 \overline{1})+I_{\mathrm{m}}(111)+I_{\mathrm{t}}(101)}
$$

where $I_{\mathrm{m}}(11 \overline{1}), I_{\mathrm{m}}(111)$ and $I_{\mathrm{t}}(101)$ are the intensity of peaks $\mathrm{m}(11 \overline{1}), \mathrm{m}(111)$ and $\mathrm{t}(101)$, respectively. The XRD pattern of the YSZ layer after thermal treatment is 
shown in Fig. 10. The calculated volume fraction of the monoclinic phase after thermal treatment is about $9.6 \%$. The corresponding linear expansion is about $0.16 \%$. Therefore, the stress caused by phase transformation $\sigma_{\mathrm{t}-\mathrm{m}}$ is compressive about 80 MPa.

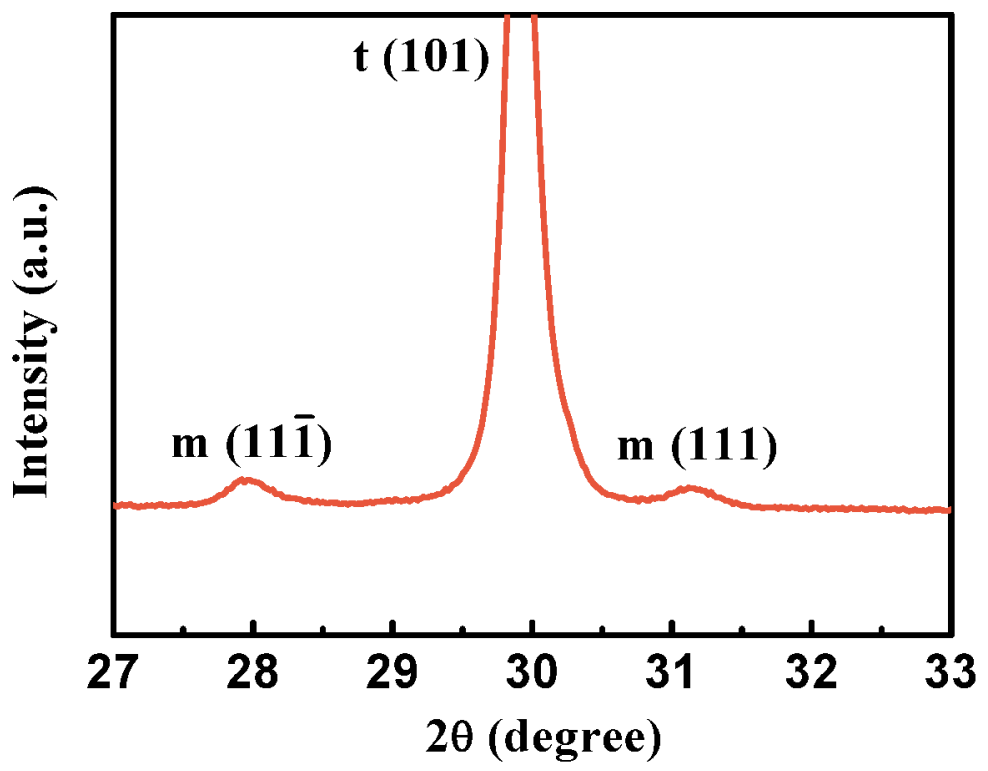

Fig. 10. The XRD spectra of the samples after 3024 -h cycles at $1150{ }^{\circ} \mathrm{C}$.

The total biaxial compressive stresses in the YSZ layer after oxidation are:

$$
\sigma=\sigma_{\text {misfit }}+\sigma_{\text {constrain }}+\sigma_{\mathrm{t}-\mathrm{m}}
$$

For the YSZ layer above a circular separation at the interface, subjected to an equibiaxial compressive stress $\sigma$, the smallest length of interface separations $b_{\mathrm{c}}$ which is the prerequisite for buckling could be calculated by: ${ }^{20}$

$$
b_{\mathrm{c}}=\sqrt{\frac{4.88 E_{\mathrm{tbc}} t_{\mathrm{tbc}}^{2}}{\sigma\left(1-v_{\mathrm{tbc}}^{2}\right)}}
$$

According to equations $1-8$, the calculated critical diameter $b_{\mathrm{c}}$ varies parabolically with spacing length, as shown in Fig. 10. The critical diameter decreases dramatically with spacing length when $L<5 \mathrm{~mm}$. This is related to the stress caused by TGO 
growth which could be neglected when $L>5 \mathrm{~mm}$

Since the YSZ layer in this experiment was segmented by the meshes. The buckling of the YSZ layer does not occur if:

$$
b_{\mathrm{c}} \geq l
$$

The critical spacing length is about $4.9 \mathrm{~mm}$ as marked in Fig. 11. This is consistent with the results that the top layer buckled for the samples with mesh spacing length about $5 \mathrm{~mm}$ and $7 \mathrm{~mm}$, while no buckling was observed for TBCs with $L=3 \mathrm{~mm}$.

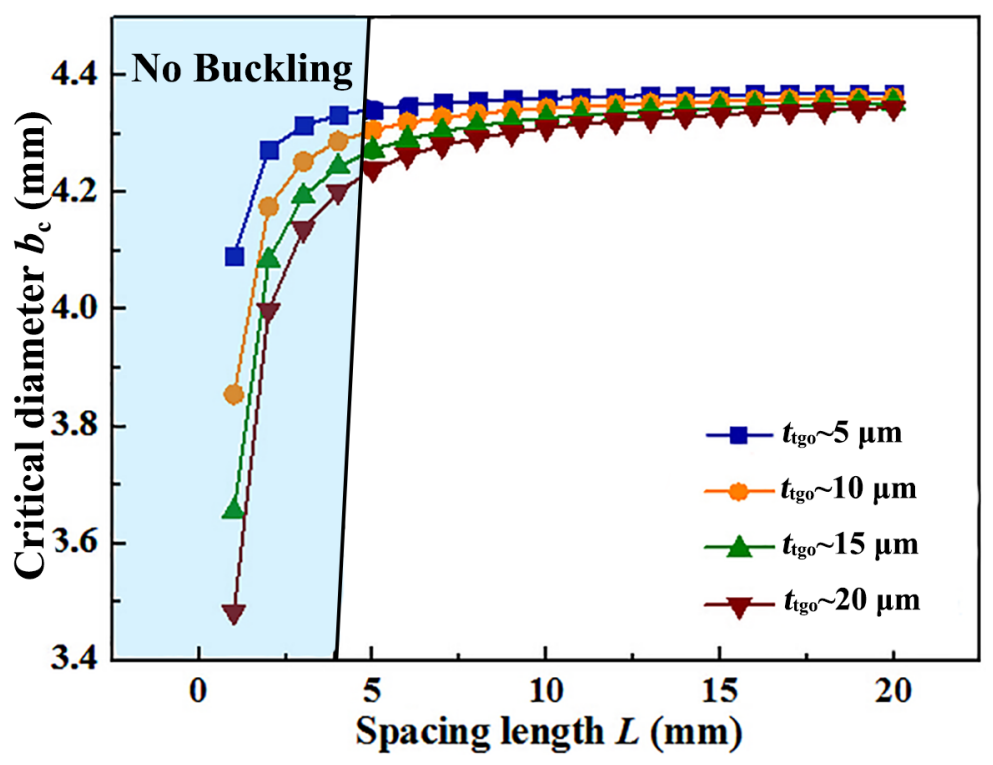

Fig. 11. The critical diameters $b_{c}$ of TBCs with mesh as a function of the spacing length $L$ and the TGO thickness $t_{\mathrm{tgo}}$.

\subsection{Crack deflection and coalescence}

In traditional TBCs, the interfacial cracks nucleate, propagate and coalesce along the YSZ/bond coat interface, leading to large scale delamination. ${ }^{21}$ For the meshed TBCs, the interfacial cracks can be arrested or deflected at the bottom of the meshes. Large scale delamination and failure occur when the deflected cracks coalesce with the ridge 
cracks. The competition between these two failure modes is related to the mesh height (since the width $w$ is fixed in this study), which is illustrated in Fig. 4. For mesh height of $70 \mu \mathrm{m}$, large edge initiated delamination forms through interfacial crack propagation, deflection and coalescence. When the mesh height is over $70 \mu \mathrm{m}$, only small pieces of coating detached around the ridge of the mesh. This indicates that the edge initiated delamination is impeded by the meshes and the mesh height plays a crucial role for the arrestment of interfacial cracks. The effect of the mesh height on the crack deflection and the critical mesh height will be discussed as follows.

The ability to deflect crack path is a primary requirement for obtaining enhanced toughness. ${ }^{22}$ When the interfacial crack encounters the mesh, the crack front is deflected out of plane by an angle $\theta$. The tilted crack has Mode I and Mode II contributions to the stress intensity. ${ }^{23}$ The toughness increment $\Gamma_{d} / \Gamma_{i}$ due to the crack deflection could be evaluated by:

$$
\frac{\Gamma_{\mathrm{d}}}{\Gamma_{\mathrm{i}}}=\frac{G_{\mathrm{i}}^{\mathrm{c}}}{G_{\mathrm{d}}^{\mathrm{c}}}
$$

where $\Gamma_{\mathrm{i}}$ is the interfacial toughness between the top coat and bond coat. $\Gamma_{\mathrm{d}}$ is the toughness related to the interfacial crack deflection. $G_{\mathrm{i}}^{\mathrm{c}}$ is the energy release rate for the interfacial crack propagating along the interface. $G_{\mathrm{d}}^{\mathrm{c}}$ is the energy release rate pertinent to each segment of the crack front along its deflected trajectory. When the length of the deflection portion of the crack is small with respect to the total crack length, the ratio of $G_{\mathrm{i}}^{\mathrm{c}} / G_{\mathrm{d}}^{\mathrm{c}}$ is: ${ }^{24}$

$$
\frac{G_{\mathrm{i}}^{\mathrm{c}}}{G_{\mathrm{d}}^{\mathrm{c}}}=q^{2}\left[|c|^{2}+|d|^{2}+2 \operatorname{Re}\left(c d \mathrm{e}^{2 \mathrm{i} \psi}\right)\right]
$$

where 


$$
q=\sqrt{\frac{1-\beta^{2}}{1+\alpha^{2}}}
$$

$\alpha$ and $\beta$ are Dunders' parameters, given by: ${ }^{25}$

$$
\begin{gathered}
\alpha=\frac{\bar{E}_{\mathrm{tbc}}-\bar{E}_{\mathrm{sub}}}{\bar{E}_{\mathrm{tbc}}+\bar{E}_{\mathrm{sub}}} \\
\beta=\frac{1}{2} \frac{\mu_{\mathrm{tbc}}\left(1-2 v_{\mathrm{sub}}\right)-\mu_{\mathrm{sub}}\left(1-2 v_{\mathrm{tbc}}\right)}{\mu_{\mathrm{tbc}}\left(1-2 v_{\mathrm{sub}}\right)+\mu_{\mathrm{sub}}\left(1-2 v_{\mathrm{tbc}}\right)}
\end{gathered}
$$

with $\bar{E}=E /\left(1-v^{2}\right)$ is the plane modulus. $\mu=E /[2(1+v)]$ is the shear modulus. $\psi$ is the phase angle. $c$ and $d$ are complex functions of the deflection angle $\theta, \alpha$ and $\beta$.

$$
\begin{gathered}
c(\theta)=\frac{1}{2} \sqrt{\frac{1-\beta}{1+\alpha}}\left(\mathrm{e}^{-\frac{\mathrm{i} \theta}{2}}+\mathrm{e}^{-\frac{3 \mathrm{i} \theta}{2}}\right) \\
d\left((\theta)=\frac{1}{2} \sqrt{\frac{1-\beta}{1-\alpha}}\left(\mathrm{e}^{-\frac{\mathrm{i} \theta}{2}}-\mathrm{e}^{-\frac{3 \mathrm{i} \theta}{2}}\right)\right.
\end{gathered}
$$

For simplicity, the deflection angle $\theta$ at the bottom of the mesh is considered to be the same for a given system, which is determined by the thickness of the bond coat $t_{\mathrm{bc}}$, the mesh height $h$ and width $w$. The deflection angle $\theta$ is:

$$
\theta= \begin{cases}\arccos \left(\frac{w^{2}-4 h^{2}+8 h t_{\mathrm{bc}}}{w^{2}+4 h^{2}+8 h t_{\mathrm{bc}}}\right), & h<\frac{w}{2} \\ 90^{\circ}, & h \geq \frac{w}{2}\end{cases}
$$

The deflection angle is determined by the ratio of $h / w$. However, for the TBCs used in the present work, the mesh width $(480 \mu \mathrm{m})$ and the thickness of the bond coat $t_{\mathrm{bc}}(150 \mu \mathrm{m})$ are fixed. Therefore, the deflection angle $\theta$ is a function of the mesh height $h$. Fig. 12 shows the $G_{\mathrm{i}}^{\mathrm{c}} / G_{\mathrm{d}}^{\mathrm{c}}$ as a function of the mesh height $h$ and deflection angle $\theta$, for various value of phase angle $\psi$, in each case $\beta=0$ to avoid the added complication associated with the oscillatory singularity. It indicates that the toughness 
increment associated with the interfacial crack deflection is determined by the mesh height $h$ (i.e., deflection angle $\theta$ ) and phase angle $\psi$.

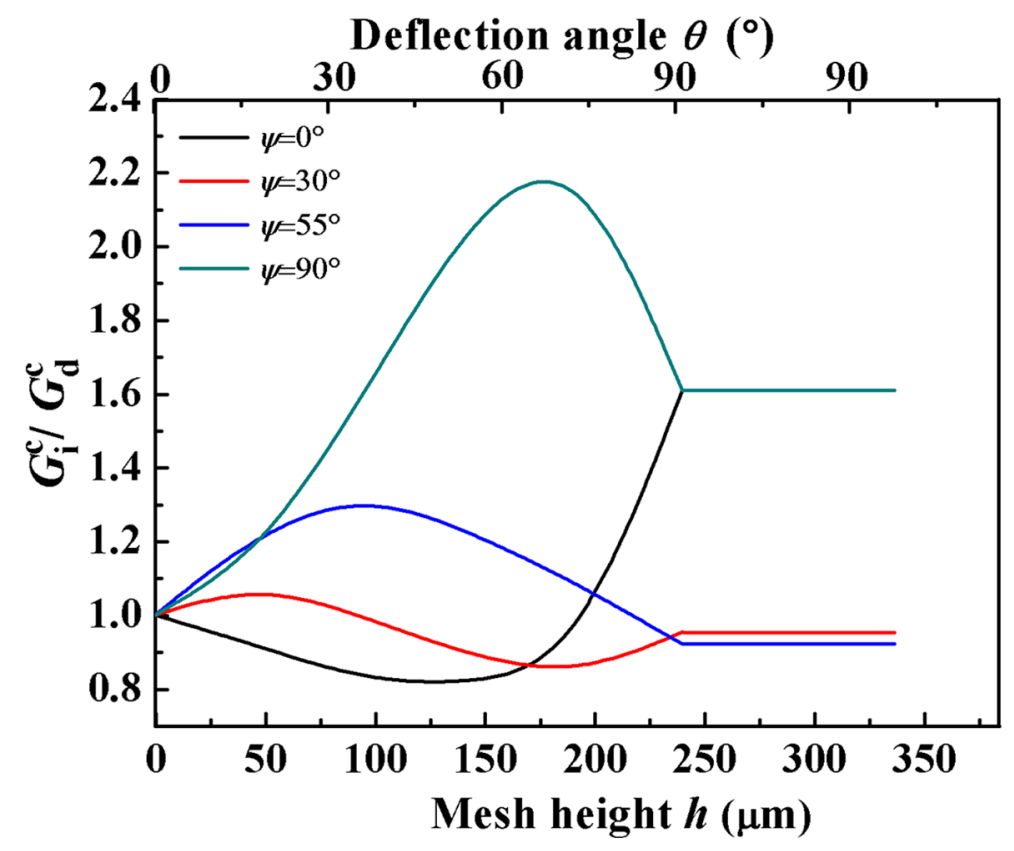

Fig. 12. Variation of $G_{\mathrm{i}}^{\mathrm{c}} / G_{\mathrm{d}}^{\mathrm{c}}$ with mesh height $h$ and deflection angle $\theta$ for various phase angle $\psi$. The width $w$ of the mesh is about $480 \mu \mathrm{m}$.

For conventional TBCs, the edge and buckle driven delamination are the two most common failure modes [26]. The edge delamination could be initiated from the physical edge of the sample or the root of the vertical cracks in the YSZ layer. The failure of the APS TBCs through edge delamination could occur along the YSZ/bond coat interface or within the YSZ layer [27-29]. The buckling of the YSZ layer normally occurs far from the edge when the interfacial cracks exceeds a critical length. For the meshed TBCs studied, the buckling and edge delamination initiated from the edge along the YSZ/bond coat interface were observed. To simplify the analysis, interfacial crack deflection of these two kinds of failure behavior is discussed in the following. 
The coating segmented by the adjacent meshes are considered as isolated units. The energy release rate over the front of the circular buckles is: ${ }^{10}$

$$
G_{\mathrm{ss}}^{\mathrm{B}}=g_{1} G_{0}\left[1-\left(\frac{\sigma_{\mathrm{c}}}{\sigma}\right)^{2}\right]
$$

where

$$
\begin{gathered}
G_{0}=\frac{\left(1-v_{\mathrm{tbc}}^{2}\right) h_{\mathrm{tbc}} \sigma^{2}}{2 E_{\mathrm{tbc}}} \\
\sigma_{\mathrm{c}}=\frac{4.88 E_{\mathrm{tbc}}}{1-v_{\mathrm{tbc}}^{2}}\left(\frac{h_{\mathrm{tbc}}}{l}\right)^{2}
\end{gathered}
$$

$\sigma$ and $G_{0}$ are the uniform compressive stress and the elastic energy per unit area stored in the unbuckled film, respectively. ${ }^{26}$

$$
g_{1}=\left[1+0.9\left(1-v_{\mathrm{sub}}\right)\right]^{-1}
$$

The tip of the buckle will deflect along the meshes when

$$
\begin{gathered}
G_{\mathrm{ss}}^{\mathrm{B}} \geq \Gamma_{\mathrm{d}}^{\mathrm{B}} \\
\Gamma_{\mathrm{d}}^{\mathrm{B}}=\Gamma_{\mathrm{i}}\left(G_{\mathrm{i}}^{\mathrm{c}} / G_{\mathrm{d}}^{\mathrm{c}}\right)
\end{gathered}
$$

where $\Gamma_{\mathrm{i}}$ is the interfacial toughness between the YSZ layer and the bond coat. $\Gamma_{\mathrm{d}}^{\mathrm{B}}$ is the toughness of the interface after crack deflection.

$$
\Gamma_{\mathrm{i}}=\Gamma_{\mathrm{I}}\left(1+\tan ^{2}(1-\lambda) \psi\right)
$$

$\Gamma_{\mathrm{I}}$ is the mode I interfacial toughness (when $\psi=90^{\circ}$ ). It is reported that the $K_{\mathrm{IC}}$ is 0.81 $\mathrm{MPa} \cdot \sqrt{\mathrm{m}}, K_{\mathrm{IIC}}=2.49 \mathrm{MPa} \cdot \sqrt{\mathrm{m}}^{30}$ Therefore, the mode II toughness $\Gamma_{\mathrm{II}}$ is about 120 $\mathrm{J} / \mathrm{m}^{2}$ and the mode I toughness $\Gamma_{\mathrm{I}}$ is about $35 \mathrm{~J} / \mathrm{m}^{2}$. Substituting in appropriate values $\left(\Gamma_{\mathrm{II}}=120 \mathrm{~J} / \mathrm{m}^{2}, \Gamma_{\mathrm{I}}=35 \mathrm{~J} / \mathrm{m}^{2}, \psi=70^{\circ}\right)$, the energy release rate of the tip of the buckles and the toughness as a function of the mesh height are plotted in Fig. 13. It shows that the spacing length should be lower than $7 \mathrm{~mm}$. In this case, the buckle will be arrested 
between the meshes.

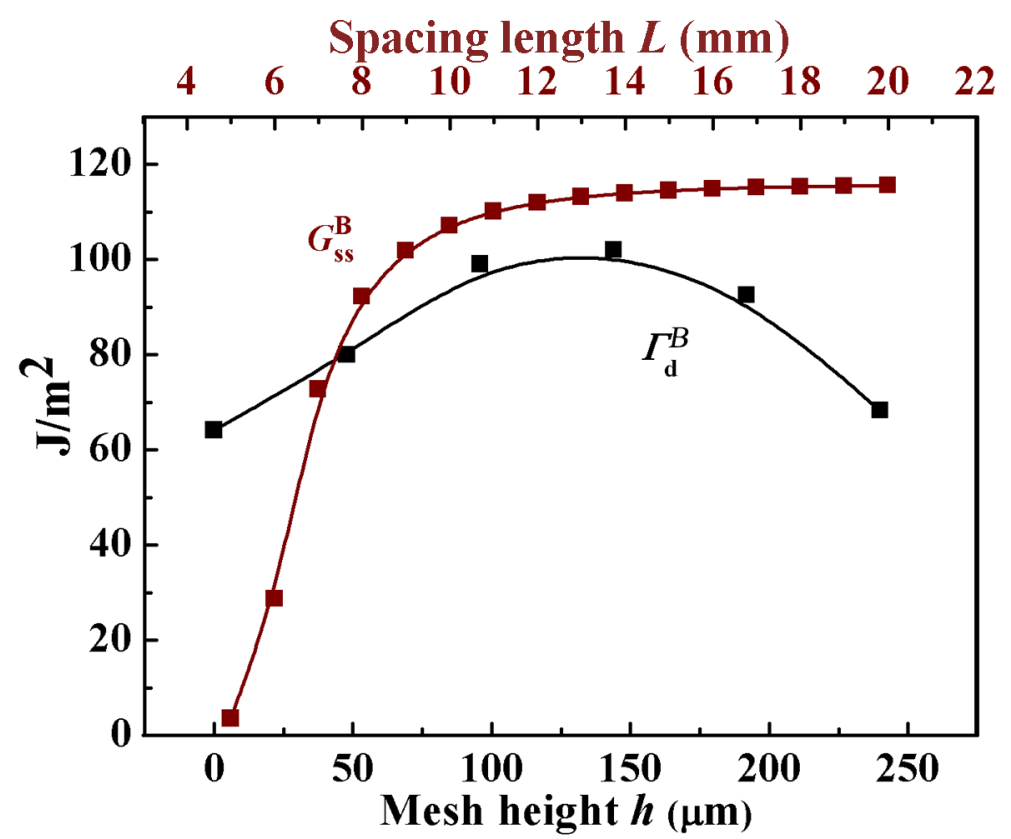

Fig. 13. The maximum energy release rate $G_{\mathrm{ss}}^{\mathrm{B}}$ of the tip of the buckle vs the spacing length $L$ (the red line) and the toughness of the interface after crack deflected $\Gamma_{\mathrm{d}}^{\mathrm{B}}$ as a function of the mesh height $h$ (the black line).

For the edge delamination of the compressed coatings, the interface crack is in strictly mode II. The criterion for the edge initiated interfacial cracks to be arrested is:

$$
G_{\mathrm{ss}}^{\mathrm{E}} \leq \Gamma_{\mathrm{d}}^{\mathrm{E}}
$$

where $G_{\mathrm{ss}}^{\mathrm{E}}$ is the steady energy release rate of the edge initiated crack. $\Gamma_{\mathrm{d}}^{\mathrm{E}}=\Gamma_{\mathrm{II}}\left(G_{i}^{c}\right)$ $G_{d}^{c}$ ), is the toughness of the interface after crack deflection. $\Gamma_{\mathrm{II}}$ is the mode II interfacial toughness (when $\psi=90^{\circ}$ ), about $120 \mathrm{~J} / \mathrm{m}^{2} \cdot{ }^{30}$ The calculated $G_{\mathrm{ss}}^{\mathrm{E}}$ approaches $200 \mathrm{~J} / \mathrm{m}^{2}$. The $\Gamma_{\mathrm{d}}^{\mathrm{E}}$ as a function of the mesh height is plotted in Fig. 14. The experiment observation for crack arrested and deflected is also superimposed. It can be seen that the critical mesh height for the edge initiated delamination is about 110 $\mu \mathrm{m}$. This is consistent with the experimental results that the edge initiated 
delamination only occurs when $\mathrm{h}<110 \mu \mathrm{m}(70 \mu \mathrm{m}$ in present experiment), but is impeded when the mesh height is over $110 \mu \mathrm{m}$.

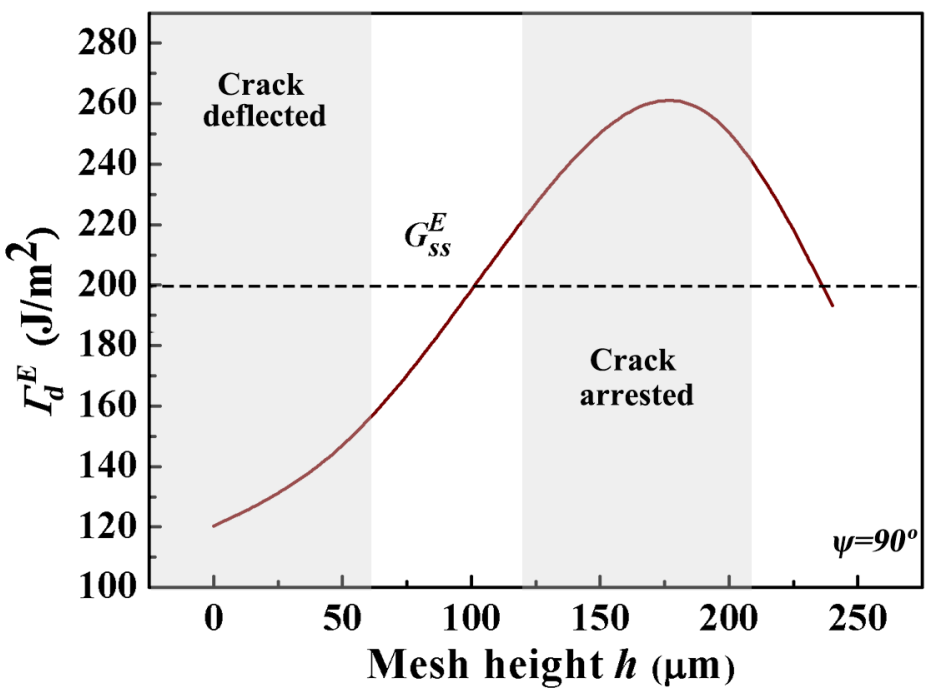

Fig. 14. The toughness of the interface after edge initiated crack deflected $\Gamma_{\mathrm{d}}^{\mathrm{E}}$ as a function of the mesh height $h$.

Meanwhile, it should be noted that the interfacial toughness is critical for the evolution of the interfacial cracks (arrested or deflected) and the YSZ/metal interface toughness has a broad range. ${ }^{31,32}$ For example, Yamazaki et al adopted four-point bending tests to study the APS YSZ/CoNiCrAlY interface and found that the interfacial toughness increased from $130 \mathrm{~J} / \mathrm{m}^{2}$ (as-deposited specimen) to $250 \mathrm{~J} / \mathrm{m}^{2}$ after aging at $1000{ }^{\circ} \mathrm{C}$ for $2000 \mathrm{~h} .{ }^{33} \mathrm{Xu}$ et al used shear test and the results range from $260 \mathrm{~J} / \mathrm{m}^{2}$ for the as-deposited TBCs to $290 \mathrm{~J} / \mathrm{m}^{2}$ for the heat treated TBCs. ${ }^{34}$ Therefore, the critical mesh height is case specific and should be evaluated based on the appropriate interfacial toughness and phase angle.

Based on the analysis above, ideally, the mesh spacing length should be lower than 7 $\mathrm{mm}$ and the mesh height $h$ higher than $110 \mu \mathrm{m}$ to maximize the possibility that 
interfacial crack would be arrested at the ridge. This seems that the YSZ layer around the ridge of mesh would be more stable with the increase of the mesh height. However, the radial tensile stress around the ridge of the mesh also increases with the mesh height (shown in Fig. 8), which is detrimental to the stability of the YSZ layer around the mesh. For the TBCs system studied in the present work, an optimized condition is with the critical mesh height about $110 \mu \mathrm{m}$ and the spacing length not exceeding $7 \mathrm{~mm}$.

\section{Conclusions}

Mesh patterns were deposited by laser powder deposition between the bond coat and the substrate. The thermal cycling tests show that mesh patterning is beneficial for the durability of the TBCs. The failure behavior and the durability of the TBCs are affected by the parameters of the mesh such as mesh spacing length $L$, height $h$, and width $w$. In general, the failure of the TBCs with mesh could proceed in three steps: (I) initiation of interfacial and ridge cracks; (II) cracks propagation and buckling; (III) interfacial cracks deflect and coalesce with ridge crack and results in failure. The analysis on the factors controlling each step illustrates that for a typical APS TBCs with YSZ thickness about $200 \mu \mathrm{m}$, the critical mesh height $h$ and spacing length $L$ is about $110 \mu \mathrm{m}$ and $7 \mathrm{~mm}$ when the mesh width $w$ is fixed at about $480 \mu \mathrm{m}$. It should be noted that the optimum parameters may be different for different thickness of YSZ layer and width of the mesh.

\section{Acknowledgement}


The authors wish to thank the financial support from the National Natural Science Foundation of China (No. 51271120 and No. 51402058).

\section{References}

1. Chevalier J, Gremillard L, Virkar, AV, et al. The Tetragonal-Monoclinic Transformation in Zirconia: Lessons Learned and Future Trends. J Am Ceram Soc. 2009;92:1901-1920.

2. Evans AG, Mumm DR, Hutchinson JW, et al. Mechanisms controlling the durability of thermal barrier coatings. Prog Mater Sci. 2001;46:505-553.

3. Padture NP, Gell M, Jordan EH, Thermal barrier coatings for gas-turbine engine applications. Sci. 2002;296:280-284.

4. Wang $\mathrm{X}$, Wang $\mathrm{C}$, Atkinson A. Interface fracture toughness in thermal barrier coatings by cross-sectional indentation. Acta Mater. 2012;60:6152-6163.

5. Kromer R, Costil S, Cormier J, et al. Laser Surface Patterning to enhance adhesion of Plasma Sprayed Coatings. Surf Coat Technol. 2015;278:171-182.

6. Smialek J. Improved oxidation life of segmented plasma sprayed 8YSZ thermal barrier coatings. J Therm Spray Technol. 2004;13:66-75.

7. Luo L, Zhang X, Zou Z, et al. Improved the Durability of Thermal Barrier Coatings with Interface Modified by Three-Dimensional Mesh Patterns. J Am Ceram Soc. 2016;99:3406-3410.

8. Ahrens M, Vassen R, Stover D. Stress distributions in plasma-sprayed thermal barrier coatings as a function of interface roughness and oxide scale thickness. Surf 
Coat Technol. 2002;161:26-35.

9. Sergo V, Clarke DR. Observation of subcritical spall propagation of a thermal barrier coating. J Am Ceram Soc. 1998;81:3237-3242.

10. Wang JS, Evans AG. Measurement and analysis of buckling and buckle propagation in compressed oxide layers on superalloy substrates. Acta Mater. 1998; 46:4993-5005.

11. Song M, Ma Y, Gong SK. Analysis of residual stress distribution along interface asperity of thermal barrier coating system on macro curved surface. Prog Nat Sci: Mater Int. 2011;21:262-267.

12. Hille TS, Nijdam TJ, Suiker ASJ, et al. Damage growth triggered by interface irregularities in thermal barrier coatings. Acta Mater. 2009;57:2624-2630.

13. Hsueh $\mathrm{CH}$, Fuller ER. Analytical modeling of oxide thickness effects on residual stresses in thermal barrier coatings. Script Mater. 2000;42:781-787.

14. He MY, Mumm DR, Evans AG. Criteria for the delamination of thermal barrier coatings: with application to thermal gradients. Surf Coat Technol. 2004;185:184-193. 15. Limarga AM, Vassen R, Clarke DR. Stress distribution in plasma-sprayed thermal barrier coatings under thermal cycling in a temperature gradient. J Appl Mech. 2011;57:011003-1-01003-9.

16. Busso EP, Qian ZQ, Taylor MP, et al. The influence of bondcoat and topcoat mechanical properties on stress development in thermal barrier coating systems. Acta Mater. 2009;57:2349-2361.

17. Witz G, Shklover V, Steurer W, et al. Phase Evolution in Yttria-Stabilized Zirconia 
Thermal Barrier Coatings Studied by Rietveld Refinement of X-Ray Powder Diffraction Patterns. J Am Ceram Soc. 2007;90:2935-2940.

18. Limarga AM, Shian S, Baram M, et al. Effect of high-temperature aging on the thermal conductivity of nanocrystalline tetragonal yttria-stabilized zirconia. Acta Mater. 2012;60:5417-5424.

19. Toraya H, Yoshimura M, Somiya S. Calibration Curve for Quantitative Analysis of the Monoclinic-Tetragonal $\mathrm{ZrO}_{2}$ System by X-Ray Diffraction. J Am Ceram Soc. 1984;67:119-121.

20. Hutchinson JW, He MY, Evans AG. The influence of imperfections on the nucleation and propagation of buckling driven delaminations. J Mech Phys Solids. 2000;48:709-734.

21. Wang JS, Evans AG,. Effects of strain cycling on buckling, cracking and spalling of a thermally grown alumina on a nickel-based bond coat. Acta Mater. 1999;47:699-710.

22. Madani K, Belhouari M, Bachir Bouiadjra B, et al. Crack deflection at an interface of alumina/metal joint: A numerical analysis. Comput Mater Sci. 2007;38:625-630.

23. Faber KT, Evans AG. Crack deflection processes-I. Theory. Acta Metall. 1983;31:565-576.

24. He MY, Hutchinson JW. Kinking of a Crack Out of an Interface. J Appl Mech. 1989;56:270-278.

25. Hutchinson RG, Hutchinson JW. Lifetime Assessment for Thermal Barrier 
Coatings: Tests for Measuring Mixed Mode Delamination Toughness. J Am Ceram Soc. 2011;94:85-95.

26. Hutchinson JW, Suo Z. Mixed Mode Cracking in Layered Materials. Adv Appl Mech. 1991;29:63-191.

27. Li CJ, Li Y, Yang GJ, et al. Evolution of lamellar interface cracks during isothermal cycling test of plasma-sprayed 8YSZ coatings with a columnar-structured YSZ interlayer. $J$ Therm Spray Technol. 2013;22:1374-1382.

28. Ahmadian S, Jordan EH. Explanation of the effect of rapid cycling on oxidation, rumpling, microcracking and lifetime of air plasma sprayed thermal barrier coatings. Surf Coat Tech. 2014;244:109-116.

29. Li CJ, Dong Hui, Ding H, et al. The correlation of the TBC lifetimes in burner cycling test with thermal gradient and furnace isothermal cycling test by TGO effects. J Therm Spray Technol. 2017;26:378-387.

30. Arai M, Kajima Y, Kishimoto K. Mixed-mode interfacial fracture toughness for thermal barrier coating. Eng Fract Mech. 2007;74:2055-2069.

31. Kim SS, Liu YF, Kagawa Y. Evaluation of interfacial mechanical properties under shear loading in EB-PVD TBCs by the pushout method. Acta Mater. $2007 ; 55: 3771-3781$

32. Zhao Y, Shinmi A, X. Zhao, Withers PJ, et al. Investigation of interfacial properties of atmospheric plasma sprayed thermal barrier coatings with four-point bending and computed tomography technique. Surf Coat Tech. 2012;206:4922-4929.

33. Yamazaki Y, Schmidt A, Scholz A. The determination of the delamination 
resistance in thermal barrier coating system by four-point bending tests. Surf Coat Tech. 2006;201:744-754.

34. Xu ZH, Yang Y, Huang P, et al. Determination of interfacial properties of thermal barrier coatings by shear test and inverse finite element method. Acta Mater. 2010;58:5972-5979. 